\title{
Prioritizing e-learning websites evaluation and selection criteria using fuzzy set theory
}

\author{
Rakesh Garg $^{\mathrm{a}^{*}}$ and Dimpal Jain ${ }^{\mathrm{a}}$
}

${ }^{a}$ Department of Computer Science \& Engineering, Hindu College of Engineering, Sonipat, Haryana, India

\begin{tabular}{l}
\hline C H R O N I C L E \\
\hline Article history: \\
Received: October 1, 2016 \\
Received in revised format: No- \\
vember 16, 2016 \\
Accepted: January 20, 2017 \\
Available online: \\
January 21, 2017 \\
\hline Keywords: \\
Selection criteria \\
Multi-criteria decision making \\
(MCDM) \\
Fuzzy set theory (FST)
\end{tabular}

\begin{abstract}
A B S T R A C T
E-learning websites evaluation and selection is extremely important for the establishment of effective E-learning. The E-learning website selection has crucial importance for the educational sector. The selection of E-learning website problem is generally considered as a Multi-Criteria Decision Making (MCDM) problem which mainly consists of both qualitative and quantitative criteria. The development of an E-learning website mainly depends on the success of the Elearning website selection along with various alternatives. So, for the effective evaluation and selection of E-learning websites, a set of selection criteria should be obtained. This paper consists of two steps, the first step is the identification of E-learning website selection criteria, second step provides the linguistic variables against the selection criteria and then fuzzy set theory (FST) is adopted for the calculation of the priority weights of each selection criteria. To show the relative importance of each selection criteria, they ranked according to their global weights.
\end{abstract}

\section{Introduction}

In this present scenario, the advancements in the information and communication technology (ICT) are opening the new circumstances in the 'E-learning'. The ICT delivers the higher education between the learners and institutions. The term 'E-learning' is an interactive form of learning, where the learning contents are available online and provide the automatic feedback to the learners. E-learning embraces a variety of electronic media for example, interactive television, video conferencing, web-based multimedia, etc. This type of learning changes the concept of traditional classroom paradigm to a learning paradigm. E-learning provides many possible benefits as (i) Cost saving (ii) Learn anywhere in anytime (iii) Convenient. Some disadvantages are also associated with the E-learning as (i) Lack of Knowledge (ii) Asynchronous communication (iii) Slow internet connection. In this study, a set of selection criteria is identified for the effective evaluation and selection of E-learning websites. The rest of the paper is prepared in six sections as: The review of previous work about the E-learning websites evaluation and selection is presented in section 2, in section 3 preliminaries of fuzzy set theory (FST) is provided; model

* Corresponding author. Tel. : 9416907980

E-mail address: rkgarg06@gmail.com (R.Garg) 
development for the selection criteria is given in section 4, results and conclusions are provided in section 5 and section 6 .

\section{Review of Previous Work}

Wands and Blanc (2001) categorized the critical success factors into three factors namely cognitive, general and organizational factors for the E-learning websites. Govindasamy (2002) considered five parameters namely student support, storing and managing content, developing content, packaging content and assessment for the effective E-learning systems. Wang (2003) developed a model for measuring the user satisfaction with asynchronous E-learning system. This study examines the reliability, criterion- related validity, content validity, nomological validity, convergent validity and discriminate validity.

MacDonald and Thompson (2005) presented the five dimensions as structure, content, delivery, service and outcomes of demand-driven learning model for the E-learning website. Nokelainen (2006) presented the usability criteria for the evaluation of learning materials and considers the following components i.e. learner activity, learner control, goal orientation, collaborative learning, added value, motivation, flexibility, feedback, motivation and valuation of previous knowledge. Selim (2007) presented critical success factors (CSFs) that are grouped into four main categories as information technology, instructor, student and university support. Sun et al. (2008) grouped E-learning critical success factors (CSFs) into six dimensions as environmental dimension, technology dimension, course dimension, learner dimension, design dimension and instructor dimension.

Ozkan and Koseler (2009) proposed a methodology for the evaluation of Learning Management System (LMS) through six dimensions namely instructor attitudes, content quality, learner perspective, supportive issues, system quality and service quality. Mehregan et al. (2011) solved the present problem by combining the FAHP (fuzzy analytic hierarchy process) method and CSFs (critical success factors). These CSFs are classified into seven basic categories as knowledge management (KM), participation interaction, instructor characteristics, content quality, IT quality, student characteristics and educational institutes support.

Alias et al. (2012) identified the ten dimensions, i.e., linkage, communication, structure and layout, information, support, appearance, security, reliability, ease of use and efficiency to ensure the success of electronic learning in higher education. Jain et al. (2015) used the TOPSIS method to solve the problem of E-learning websites selection based on selection criteria. Jain et al. (2016) proposed a WDBA methodology for the ranking of E-learning websites using six selection criteria as security, interactivity, complete content, personalization, right and understandable content, user interface and navigation.

\section{Preliminaries of Fuzzy Set Theory (FST)}

Zadeh (1965) proposed the fuzzy set theory which is capable to deal with the impreciseness and vagueness of data. A fuzzy set is a set of objects in which the membership function lies in the interval of zero and one. FST has been already applied in various fields, i.e. control theory, scientific environment, robotics, etc. Triangular fuzzy numbers (TFN's) is usually adopted to capture the vagueness of data related to the decision-making process. A TFN is defined by three parameters $P=(h \mathrm{~m}, 1)$ where $h$ is the highest parameter value, $\mathrm{m}$ is middle parameter value and $l$ is the lowest parameter value which can be represented as: 


$$
\mu_{P}(x)= \begin{cases}(x-h) /(m-h) & \text { if } h \leq x \leq m, \\ (l-x) /(l-m) & \text { if } m \leq x \leq l \\ 0 & \text { otherwise }\end{cases}
$$

\subsection{Linguistic variables}

In this paper, ten point fuzzy scale, i.e. extremely most important, very very most important, very most important, most important, important, less important, very less important, very very less important, extremely less important and not important are used for the weights of the selection criteria. The conversion of linguistic variables into membership function is shown in Table 1.

\section{Table 1}

Linguistic variables for the weight of each selection criteria

\begin{tabular}{lclc}
\hline \multicolumn{1}{c}{ Linguistic Variables } & $\begin{array}{c}\text { Membership } \\
\text { Functions }\end{array}$ & Linguistic Variables & $\begin{array}{c}\text { Membership } \\
\text { Functions }\end{array}$ \\
\hline Extremely Most Important (EMI) & $(9,10,10)$ & Less Important (LI) & $(4,5,6)$ \\
Very Very Most Important (VVMI) & $(8,9,10)$ & Very Less Important (VLI) & $(3,4,5)$ \\
Very Most Important (VMI) & $(7,8,9)$ & Very Very Less Important (VVLI) & $(2,3,4)$ \\
Most Important (MI) & $(6,7,8)$ & Extremely Less Important (EMI) & $(1,2,3)$ \\
Important (I) & $(5,6,7)$ & Not Important (NI) & $(1,1,2)$ \\
\hline
\end{tabular}

\section{Model Development}

\subsection{Identification of E-learning websites selection criteria}

In the past researches, a number of selection criteria were proposed for the selection of E-learning website. In the present study, we identified the most suitable selection criteria for the E-learning websites. Total forty-five selection criteria are identified and grouped into two main broad categories (i) Quality factors and (ii) E-learning specific factors. Fig. 1 shows the six- level hierarchy structure for the E-learning website selection problem. The objective of our problem is the selection of E-learning website in the first level. The second level contains the two criteria (i) Quality factors and (ii) E-learning specific factors. The third and fourth level of the hierarchy consists of 10 sub-criteria and 35 sub subcriteria. The fifth level of the hierarchy is used to calculate the priority weights to get the importance of the criteria. Finally, the last level deals with the best E-learning website.

\subsection{Data gathering}

In this study, data is collected from five experts (E1, E2, E3, E4, and E5) by providing a well-designed questionnaire. These experts provide the data in form of linguistic variables using the ten point fuzzy scale. The data in the linguistic variables are then converted into the triangular fuzzy numbers (TFN's) and finally, these TFN's are converted into a single numeric value known as crisp value is obtained by applying arithmetic operations as given in Table 2 . To check the reliability of the data provided by the experts, a reliability test was performed using SPSS (Statistical package for Social Science) software. The value of Cronbach's Alpha is obtained was greater than 0.6 that shows the higher reliability and consistency of the data provided by the experts. The weights of the selection criteria in linguistic variables on a ten point fuzzy scale provided by the five experts are given in Appendix-1. 


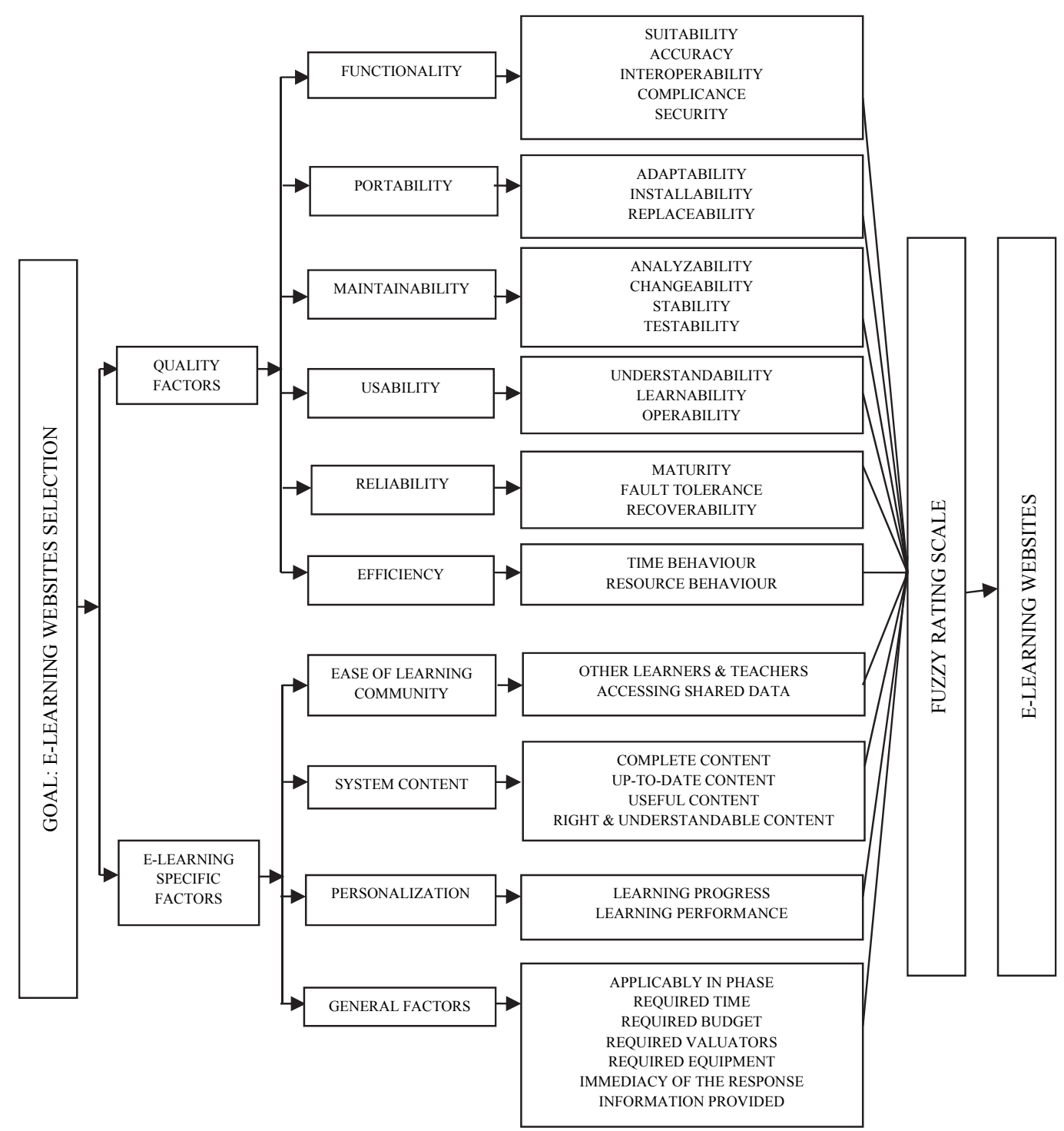

Table 2

Fig. 1. Hierarchical structure of E-learning websites selection criteria

Crisp score for the selection criteria

\begin{tabular}{|c|c|c|c|c|c|c|c|c|c|c|c|c|c|}
\hline S. No. & Selection Criteria & E1 & E2 & E3 & E4 & E5 & S. No. & Selection Criteria & E1 & E2 & E3 & E4 & E5 \\
\hline A & Quality Factors & & & & & & B & E-learning Specific Factors & & & & & \\
\hline 1 & Functionality & 9.66 & 9 & 9 & 9.66 & 8 & 7 & Ease of learning community & 9 & 8 & 8 & 7 & 8 \\
\hline 1.1 & Suitability & 9 & 9 & 8 & 6 & 8 & 7.1 & Other learners and teachers & 6 & 7 & 5 & 6 & 6 \\
\hline 1.2 & Accuracy & 7 & 8 & 8 & 8 & 7 & 7.2 & Accessing shared data & 6 & 5 & 4 & 5 & 4 \\
\hline 1.3 & Interoperability & 7 & 8 & 8 & 6 & 7 & 8 & System content & 7 & 8 & 8 & 8 & 7 \\
\hline 1.4 & Compliance & 7 & 7 & 7 & 8 & 6 & 8.1 & Up-to-date content & 6 & 6 & 5 & 6 & 5 \\
\hline 1.5 & Security & 7 & 8 & 7 & 8 & 9 & 8.2 & Sufficient content & 6 & 4 & 3 & 2 & 1.33 \\
\hline 2 & Portability & 9 & 8 & 9.66 & 8 & 9 & 8.3 & Useful content & 6 & 8 & 7 & 5 & 6 \\
\hline 2.1 & Adaptability & 8 & 8 & 7 & 8 & 8 & 8.4 & Right \& understandable content & 7 & 6 & 5 & 3 & 5 \\
\hline 2.2 & Installability & 7 & 8 & 6 & 7 & 6 & 9 & Personalization & 7 & 8 & 7 & 8 & 9 \\
\hline 2.3 & Replaceability & 7 & 6 & 7 & 8 & 7 & 9.1 & Learning progress & 6 & 7 & 5 & 6 & 7 \\
\hline 3 & Maintainability & 9 & 9 & 8 & 9 & 9 & 9.2 & Learning performance & 4 & 2 & 3 & 5 & 3 \\
\hline 3.1 & Analyzability & 8 & 6 & 8 & 9 & 7 & 10 & General factors & 8 & 7 & 6 & 8 & 8 \\
\hline 3.2 & Changeability & 7 & 8 & 6 & 6 & 7 & 10.1 & Applicably in Phase & 5 & 7 & 7 & 5 & 5 \\
\hline 3.3 & Stability & 7 & 6 & 6 & 6 & 5 & 10.2 & Required Time & 5 & 6 & 7 & 7 & 6 \\
\hline 3.4 & Testability & 8 & 6 & 6 & 6 & 7 & 10.3 & Required Budget & 8 & 7 & 7 & 5 & 6 \\
\hline 4 & Usability & 9 & 8 & 9 & 8 & 8 & 10.4 & Required Valuators & 5 & 4 & 2 & 4 & 3 \\
\hline 4.1 & Understandability & 7 & 7 & 6 & 8 & 7 & 10.5 & Required Equipment & 6 & 6 & 5 & 7 & 6 \\
\hline 4.2 & Learnability & 4 & 5 & 5 & 6 & 7 & 10.6 & Immediacy of the response & 5 & 7 & 6 & 6 & 4 \\
\hline 4.3 & Operability & 6 & 5 & 6 & 7 & 6 & 10.7 & Information Provided & 4 & 6 & 5 & 5 & 4 \\
\hline 5 & Reliability & 9 & 9 & 8 & 8 & 9 & & & & & & & \\
\hline 5.1 & Maturity & 4 & 6 & 7 & 7 & 6 & & & & & & & \\
\hline 5.2 & Fault Tolerance & 3 & 5 & 5 & 5 & 3 & & & & & & & \\
\hline 5.3 & Recoverability & 7 & 7 & 6 & 7 & 7 & & & & & & & \\
\hline 6 & Efficiency & 9 & 9 & 8 & 7 & 8 & & & & & & & \\
\hline 6.1 & Time Behavior & 7 & 7 & 5 & 7 & 7 & & & & & & & \\
\hline 6.2 & Resource Behavior & 6 & 7 & 5 & 4 & 5 & & & & & & & \\
\hline
\end{tabular}




\subsection{Weights (Local and Global) calculation}

The local and global weights of each selection criteria are calculated using fuzzy set theory as explained in section-3 and given in Table 3.

Table 3

Local and Global weights of selection criteria

\begin{tabular}{|c|c|c|c|c|c|c|c|}
\hline $\begin{array}{l}\text { S. } \\
\text { No. }\end{array}$ & Selection Criteria & $\begin{array}{c}\text { Local } \\
\text { Weight }\end{array}$ & $\begin{array}{l}\text { Global } \\
\text { Weight }\end{array}$ & $\begin{array}{c}\text { S. } \\
\text { No. }\end{array}$ & Selection Criteria & $\begin{array}{c}\text { Local } \\
\text { Weight }\end{array}$ & $\begin{array}{l}\text { Global } \\
\text { Weight }\end{array}$ \\
\hline A & Quality Factors & & & & & & \\
\hline 1 & Functionality & 0.10970 & 0.10970 & 6 & Efficiency & 0.09929 & 0.09929 \\
\hline 1.1 & Suitability & 0.21277 & 0.02334 & 6.1 & Time Behavior & 0.55000 & 0.05461 \\
\hline 1.2 & Accuracy & 0.20213 & 0.02217 & 6.2 & Resource Behavior & 0.45000 & 0.04468 \\
\hline 1.3 & Interoperability & 0.19149 & 0.02101 & B & E-learning Specific Factors & & \\
\hline 1.4 & Compliance & 0.18617 & 0.02042 & 7 & Ease of learning community & 0.09686 & 0.09686 \\
\hline 1.5 & Security & 0.20745 & 0.02276 & 7.1 & Other learners and teachers & 0.55556 & 0.05381 \\
\hline 2 & Portability & 0.10570 & 0.10570 & 7.2 & Accessing shared data & 0.44444 & 0.04305 \\
\hline 2.1 & Adaptability & 0.36111 & 0.03817 & 8 & System content & 0.09202 & 0.09202 \\
\hline 2.2 & Installability & 0.31481 & 0.03328 & 8.1 & Up-to-date content & 0.27370 & 0.02519 \\
\hline 2.3 & Replaceability & 0.32407 & 0.03425 & 8.2 & Sufficient content & 0.15934 & 0.01466 \\
\hline 3 & Maintainability & 0.10655 & 0.10655 & 8.3 & Useful content & 0.31281 & 0.02878 \\
\hline 3.1 & Analyzability & 0.28148 & 0.02999 & 8.4 & Right \& understandable content & 0.25415 & 0.02339 \\
\hline 3.2 & Changeability & 0.25185 & 0.02683 & 9 & Personalization & 0.09444 & 0.09444 \\
\hline 3.3 & Stability & 0.22222 & 0.02368 & 9.1 & Learning progress & 0.64583 & 0.06099 \\
\hline 3.4 & Testability & 0.24444 & 0.02605 & 9.2 & Learning performance & 0.35417 & 0.03345 \\
\hline 4 & Usability & 0.10171 & 0.10171 & 10 & General factors & 0.08960 & 0.08960 \\
\hline 4.1 & Understandability & 0.38043 & 0.03869 & 10.1 & Applicably in Phase & 0.15026 & 0.01346 \\
\hline 4.2 & Learnability & 0.29348 & 0.02985 & 10.2 & Required Time & 0.16062 & 0.01439 \\
\hline 4.3 & Operability & 0.32609 & 0.03317 & 10.3 & Required Budget & 0.17098 & 0.01532 \\
\hline 5 & Reliability & 0.10413 & 0.10413 & 10.4 & Required Valuators & 0.09326 & 0.00836 \\
\hline 5.1 & Maturity & 0.35294 & 0.03675 & 10.5 & Required Equipment & 0.15544 & 0.01393 \\
\hline 5.2 & Fault Tolerance & 0.24706 & 0.02573 & 10.6 & Immediacy of the Response & 0.14508 & 0.01300 \\
\hline 5.3 & Recoverability & 0.40000 & 0.04165 & 10.7 & Information Provided & 0.12435 & 0.01114 \\
\hline
\end{tabular}

\subsection{Ranking of selection criteria weights}

After calculating the local and global weights of each selection criteria, the results are now arranged in descending order and ranked according to their global weights, as represented in the Tables (4-5).

\section{Table 4}

Rankings of sub-criteria weights

\begin{tabular}{|c|c|c|}
\hline Sub-Criteria & Global Weight & Rank \\
\hline Functionality & 0.10970 & 1 \\
\hline Maintainability & 0.10655 & 2 \\
\hline Portability & 0.10570 & 3 \\
\hline Reliability & 0.10413 & 4 \\
\hline Usability & 0.10171 & 5 \\
\hline Efficiency & 0.09929 & 6 \\
\hline Ease of learning community & 0.09686 & 7 \\
\hline Personalization & 0.09444 & 8 \\
\hline System content & 0.09202 & 9 \\
\hline General factors & 0.08960 & 10 \\
\hline
\end{tabular}

Table 5

Rankings of sub sub-criteria weights

\begin{tabular}{|c|c|c|c|c|c|}
\hline Sub Sub-Criteria & Global Weight & Rank & Sub & Global & Rank \\
\hline Learning progress & 0.06099 & 1 & Fault & 0.02573 & 19 \\
\hline Time Behavior & 0.05461 & 2 & Up-to- & 0.02519 & 20 \\
\hline Other learners and teachers & 0.05381 & 3 & Stabil- & 0.02368 & 21 \\
\hline Resource Behavior & 0.04468 & 4 & Right & 0.02339 & 22 \\
\hline Accessing shared data & 0.04305 & 5 & Suita- & 0.02334 & 23 \\
\hline Recoverability & 0.04165 & 6 & Secu- & 0.02276 & 24 \\
\hline Understandability & 0.03869 & 7 & Accu- & 0.02217 & 25 \\
\hline Adaptability & 0.03817 & 8 & In- & 0.02101 & 26 \\
\hline Maturity & 0.03675 & 9 & Com- & 0.02042 & 27 \\
\hline Replaceability & 0.03425 & 10 & Re- & 0.01532 & 28 \\
\hline Learning performance & 0.03345 & 11 & Suffi- & 0.01466 & 29 \\
\hline Installability & 0.03328 & 12 & Re- & 0.01439 & 30 \\
\hline Operability & 0.03317 & 13 & Re- & 0.01393 & 31 \\
\hline Analyzability & 0.02999 & 14 & Appli- & 0.01346 & 32 \\
\hline Learnability & 0.02985 & 15 & Imme- & 0.01300 & 33 \\
\hline Useful content & 0.02878 & 16 & Infor- & 0.01114 & 34 \\
\hline Changeability & 0.02683 & 17 & Re- & 0.00836 & 35 \\
\hline Testability & 0.02605 & 18 & & & \\
\hline
\end{tabular}




\section{Results}

According to the methodology adopted in the present research, the maximum value of global weights depicts the better ranking. The rankings of all ten selection sub-criteria using global weights are given in Fig. 2. It depicts that 'functionality' sub-criteria is ranked as the most important sub-criteria having the maximum value of global weight as 0.10970 followed by 'maintainability' with global weight equals to 0.10655. 'General factors' sub-criteria is found the least important selection sub-criteria with the least value of global weight as 0.08960 .

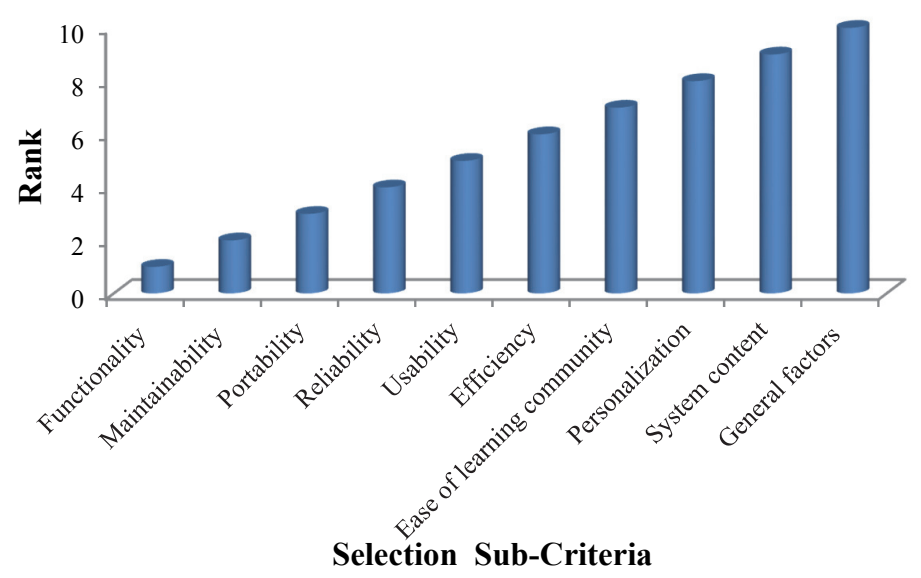

Fig. 2. Rankings of E-learning websites selection sub-criteria

The global weights of each selection sub sub-criteria are also calculated and all the sub sub-criteria are ranked according to their priority weights. It is observed that the 'Learning progress' sub sub-criteria is ranked at position number-1 having the maximum value of the global weight, i.e. 0.06099 followed by 'Time behavior', 'Other learner and teachers', 'Resource behavior', 'Accessing shared data' are ranked at position number- 2, 3, 4, 5 and the 'required valuators' sub sub-criteria is ranked at position number-35 having the minimum value of the global weight, i.e. 0.00836. The rankings of all the thirtyfive selection sub sub-criteria using global weights are given in Fig. 3.

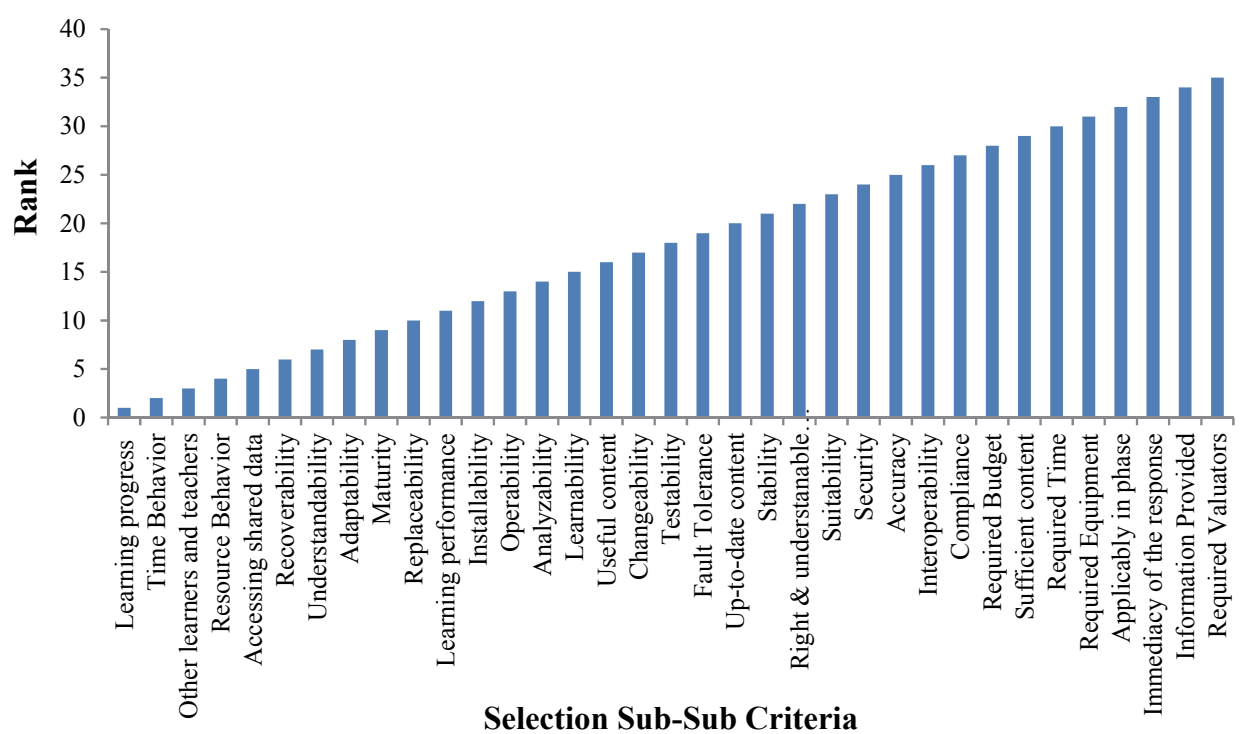

Fig. 3. Rankings of E-learning websites selection sub sub-criteria 


\section{Conclusion}

Depending on various selection criteria, the evaluation and selection of E-learning websites is a very challenging task for the developers. The main aim of this work was the identification of selection criteria process. Then, fuzzy set theory (FST) is applied to calculate the priority weights of the E-learning websites selection criteria. The proposed FST method is very appropriate to overcome the uncertainty and vagueness of the data in a real world circumstance.

\section{References}

Alias, N., Zakariah, Z., Ismail, N. Z., \& Aziz, M. N. A. (2012). E-Learning successful elements for higher learning institution in Malaysia. Procedia-Social and Behavioral Sciences, 67, 484-489.

Govindasamy, T. (2002). Successful implementation of e-learning: Pedagogical considerations. The internet and higher education, 4(3), 287-299.

Jain, D., Garg, R., \& Bansal, A. (2015). A Parameterized Selection and Evaluation of E-Learning Websites Using Topsis Method. International Journal of Research \& Development in Technology and Management Science, 22(3), 12-26.

Jain, D., Garg, R., Bansal, A., \& Saini, K. K. (2016). Selection and ranking of E-learning websites using weighted distance-based approximation. Journal of Computers in Education, 3(2), 193-207.

Wands, M., \& Le Blanc, A. (2001). Critical Success Factors: eLearning Solutions. The Official e-Newsletter of the Change and Learning Practice, Internet Time Group, Berkeley, California.

MacDonald, C. J., \& Thompson, T. L. (2005). Structure, content, delivery, service, and outcomes: Quality e-learning in higher education. The International Review of Research in Open and Distributed Learning, 6(2).

Mehregan, M. R., Jamporazmey, M., Hosseinzadeh, M., \& Mehrafrouz, M. (2011, September). Proposing an approach for evaluating e-learning by integrating critical success factor and fuzzy AHP. In International conference on innovation, management and service, Singapore.

Nokelainen, P. (2006). An empirical assessment of pedagogical usability criteria for digital learning material with elementary school students. Educational Technology \& Society, 9(2), 178-197.

Ozkan, S., \& Koseler, R. (2009, October). Multi-dimensional evaluation of e-learning systems in the higher education context: an empirical investigation of a computer literacy course. In Frontiers in Education Conference, 2009. FIE'09. 39th IEEE (pp. 1-6). IEEE.

Selim, H. M. (2007). Critical success factors for e-learning acceptance: Confirmatory factor models. Computers \& Education, 49(2), 396-413.

Sun, P. C., Tsai, R. J., Finger, G., Chen, Y. Y., \& Yeh, D. (2008). What drives a successful e-Learning? An empirical investigation of the critical factors influencing learner satisfaction. Computers \& Education, 50(4), 1183-1202.

Wang, Y. S. (2003). Assessment of learner satisfaction with asynchronous electronic learning systems. Information \& Management, 41(1), 75-86.

Zadeh L. A. (1965). Fuzzy sets. Information and Control, 8, 338-353. 


\section{Appendix 1}

Linguistic variables provided by the experts for the selection criteria

\begin{tabular}{|c|c|c|c|c|c|c|}
\hline S. No. & Criteria/Sub-Criteria & E1 & $\mathrm{E} 2$ & E3 & $\mathrm{E} 4$ & E5 \\
\hline $\mathrm{A}$ & Quality Factors & & & & & \\
\hline 1 & Functionality & EMI & VVMI & VVMI & EMI & VMI \\
\hline 1.1 & Suitability & VVMI & VVMI & VMI & I & VMI \\
\hline 1.2 & Accuracy & MI & VMI & VMI & VMI & MI \\
\hline 1.3 & Interoperability & MI & VMI & VMI & I & MI \\
\hline 1.4 & Compliance & MI & MI & MI & VMI & I \\
\hline 1.5 & Security & MI & VMI & MI & VMI & VVMI \\
\hline 2 & Portability & VVMI & VMI & EMI & VMI & VVMI \\
\hline 2.1 & Adaptability & VMI & VMI & MI & VMI & VMI \\
\hline 2.2 & Installability & MI & VMI & I & MI & I \\
\hline 2.3 & Replaceability & MI & I & MI & VMI & MI \\
\hline 3 & Maintainability & VVMI & VVMI & VMI & VVMI & VVMI \\
\hline 3.1 & Analyzability & VMI & I & VMI & VVMI & MI \\
\hline 3.2 & Changeability & MI & VMI & I & I & MI \\
\hline 3.3 & Stability & MI & I & I & I & LI \\
\hline 3.4 & Testability & VMI & I & I & I & MI \\
\hline 4 & Usability & VVMI & VMI & VVMI & VMI & VMI \\
\hline 4.1 & Understandability & MI & MI & I & VMI & MI \\
\hline 4.2 & Learnability & VLI & LI & LI & I & MI \\
\hline 4.3 & Operability & I & LI & I & MI & I \\
\hline 5 & Reliability & VVMI & VVMI & VMI & VMI & VVMI \\
\hline 5.1 & Maturity & VLI & I & MI & MI & I \\
\hline 5.2 & Fault Tolerance & VVLI & LI & LI & LI & VVLI \\
\hline 5.3 & Recoverability & MI & MI & I & MI & MI \\
\hline 6 & Efficiency & VVMI & VVMI & VMI & MI & VMI \\
\hline 6.1 & Time Behavior & MI & MI & LI & MI & MI \\
\hline 6.2 & Resource Behavior & I & MI & LI & VLI & LI \\
\hline $\mathrm{B}$ & E-learning specific factors & & & & & \\
\hline 7 & Ease of learning community & VVMI & VMI & VMI & MI & VMI \\
\hline 7.1 & Other learners and teachers & I & MI & LI & I & I \\
\hline 7.2 & Accessing shared data & I & LI & VLI & LI & VLI \\
\hline 8 & System content & MI & VMI & VMI & VMI & MI \\
\hline 8.1 & Up-to-date content & I & I & LI & I & LI \\
\hline 8.2 & Sufficient content & I & VLI & VVLI & ELI & NI \\
\hline 8.3 & Useful content & I & VMI & MI & LI & I \\
\hline 8.4 & Right \& understandable content & MI & I & LI & VVLI & LI \\
\hline 9 & Personalization & MI & VMI & MI & VMI & VVMI \\
\hline 9.1 & Learning progress & I & MI & LI & I & MI \\
\hline 9.2 & Learning performance & VLI & ELI & VVLI & LI & VVLI \\
\hline 10 & General factors & VMI & MI & I & VMI & VMI \\
\hline 10.1 & Applicably in phase & LI & MI & MI & LI & LI \\
\hline 10.2 & Required Time & LI & I & MI & MI & I \\
\hline 10.3 & Required Budget & VMI & MI & MI & LI & I \\
\hline 10.4 & Required Valuators & LI & VLI & ELI & VLI & VVLI \\
\hline 10.5 & Required Equipment & I & I & LI & MI & I \\
\hline 10.6 & Immediacy of the response & LI & MI & I & I & VLI \\
\hline 10.7 & Information Provided & VLI & I & LI & LI & VLI \\
\hline
\end{tabular}

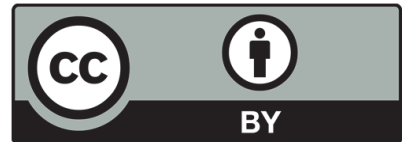

(C) 2017 by the authors; licensee Growing Science, Canada. This is an open access article distributed under the terms and conditions of the Creative Commons Attribution (CC-BY) license (http://creativecommons.org/licenses/by/4.0/). 